\section{Endoscopic ultrasound-guided antegrade diather- mic dilation followed by self-expandable metal stent placement for malignant distal biliary stricture}

Endoscopic ultrasound (EUS)-guided antegrade stenting (AGS) is established as an alternative interventional technique in patients in whom endoscopic transpapil- lary stenting has failed $[1,2]$. Here, we present a patient who underwent EUSAGS after diathermic dilation with placement of a self-expandable metal stent
(SEMS) for a malignant distal biliary stricture.

A 58-year-old woman with cancer of unknown origin and obstructive jaundice was referred to our hospital. She had undergone transpapillary stenting using a plastic stent at another hospital 2 months previously. Esophagogastroduodenoscopy (EGD) to reach the papilla of Vater was not feasible because of gastric outlet obstruction. Therefore, we attempted EUS-AGS via the stomach. First the intrahepatic bile
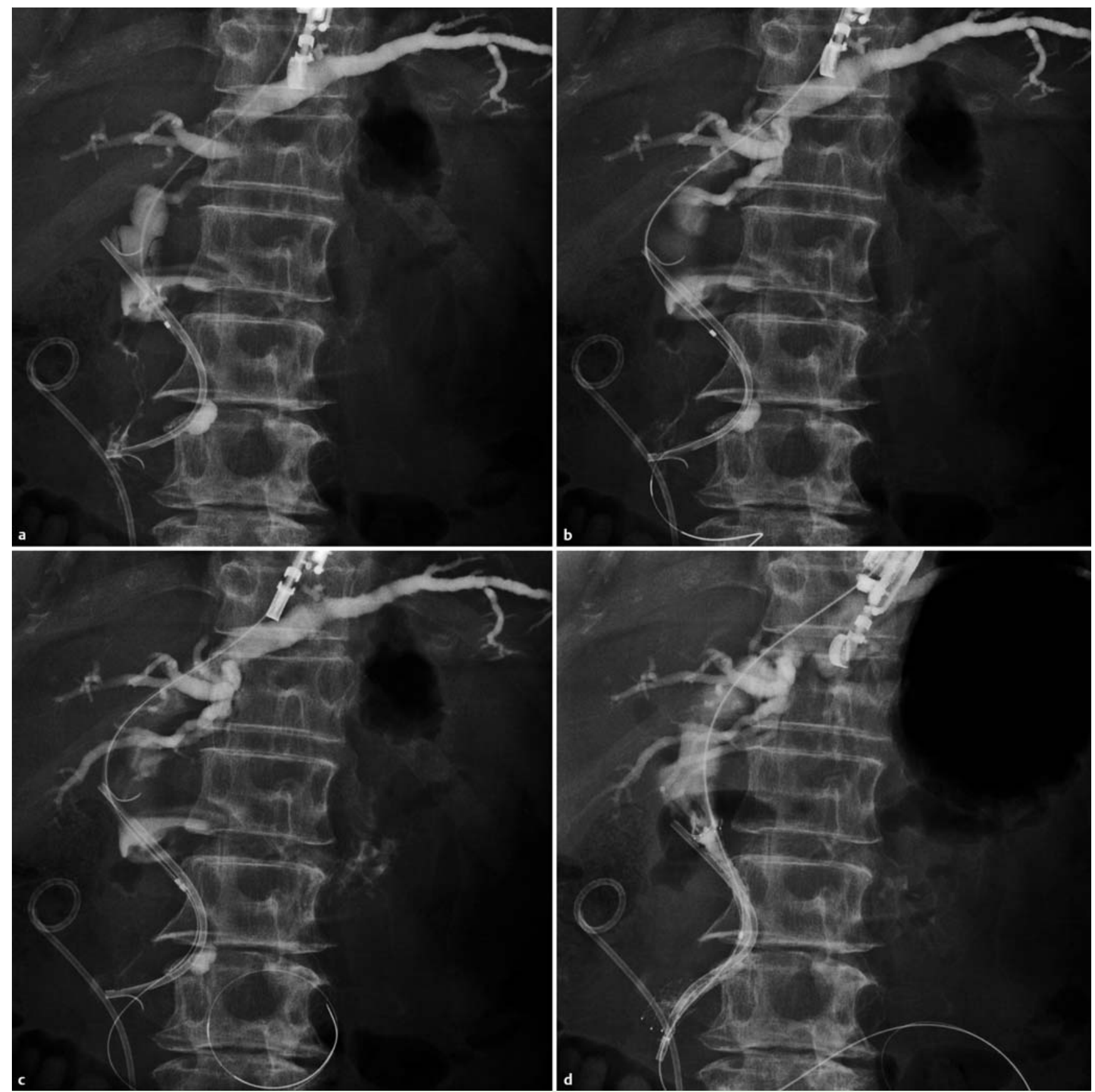

Fig. 1 Radiographic images showing: a a guidewire that has been advanced into the duodenum across the distal biliary stricture and the plastic stent that was previously placed via the transpapillary approach; $\mathbf{b}$ the tapered endoscopic retrograde cholangiopancreatography (ERCP) catheter that could not be advanced across the stricture; $\mathbf{c}$ the wire-guided diathermic dilation being performed; $\mathbf{d}$ free drainage of contrast after endoscopic ultrasound-guided antegrade wireguided diathermic dilation and antegrade placement of a biliary self-expandable metal stent (SEMS). 
duct was punctured using a 19-gauge needle and an EUS-guided cholangiogram was performed. Following this a 0.025 -inch guidewire was advanced across the stricture alongside the plastic stent under fluoroscopic guidance ( Fig. 1 a). Thereafter, we tried to dilate the stricture using a tapered endoscopic retrograde cholangiopancreatography (ERCP) catheter, but it was not possible to pass the catheter across the stricture ( $\bullet$ Fig. $\mathbf{1}$ b).

We then performed a dilation of the stricture using a 6-Fr wire-guided diathermic dilator (Cysto-Gastro-Set; EndoFlex, GmbH, Voerde, Germany) with a blended cut mode ( $\bullet$ Fig. 1 c). Finally, an uncovered SEMS with a fine delivery system (Zilver635; Cook Japan, Tokyo, Japan) was placed across the stricture alongside the obstructed plastic stent without any complications ( $\bullet$ Fig. 1 d; $\bullet$ Video 1 ).

Recently, EUS-AGS using a tapered ERCP catheter and an uncovered SEMS with a fine delivery system has been reported [3]. We also reported EUS-guided ante-

\section{Video 1}

Endoscopic ultrasound (EUS)-guided antegrade diathermic dilation and stenting for a severe refractory distal biliary stricture following conventional transpapillary stenting. grade wire-guided diathermic dilation followed by SEMS placement for refractory severe benign biliary stricture [4]. To our knowledge, this is the first report of combined EUS-AGS with diathermic dilation and placement of an uncovered SEMS for a malignant biliary stricture. EUS-guided antegrade wire-guided diathermic dilation is useful for severe strictures that cannot be dilated with conventional techniques as well as for the transpapillary approach [5].

\section{Endoscopy_UCTN_Code_TTT_1AS_2AD}

\section{Competing interests: None}

\section{Hiroshi Kawakami, Masaki Kuwatani, Kazumichi Kawakubo, Taiki Kudo, Yoko Abe, Kimitoshi Kubo, Yoshimasa Kubota, Naoya Sakamoto}

Department of Gastroenterology and Hepatology, Hokkaido University Graduate School of Medicine, Sapporo, Japan

\section{References}

1 Nguyen-Tang T, Binmoeller KF, Sanchez-Yague A. Endoscopic ultrasound (EUS)-guided transhepatic anterograde self-expandable metal stent (SEMS) placement across malignant biliary obstruction. Endoscopy 2010; 42: $232-236$
2 Artifon EL, Safatle-Ribeiro AV, Ferreira FC et al. EUS-guided antegrade transhepatic placement of a self-expandable metal stent in hepatico-jejunal anastomosis. JOP 2011; 12: 610-613

3 Ogura T, Masuda D, Imoto A et al. EUS-guided hepaticogastrostomy combined with fine-gauge antegrade stenting: a pilot study. Endoscopy 2014; 46: 416-421

4 Kawakami H, Kuwatani M, Sakamoto N. Endoscopic ultrasound-guided antegrade diathermic dilation followed by self-expandable metallic stent placement for anastomotic stricture after hepaticojejunostomy (with video). Dig Endosc 2014; 26: 121 - 122

5 Kawakami H, Kuwatani M, Kawakubo Ket al. Transpapillary dilation of refractory severe biliary stricture or main pancreatic duct by using a wire-guided diathermic dilator (with video). Gastrointest Endosc 2014; 79: $338-343$

\section{Bibliography}

DOI http://dx.doi.org/

10.1055/s-0034-1377223

Endoscopy 2014; 46: E328-E329

(c) Georg Thieme Verlag KG

Stuttgart · New York

ISSN 0013-726X

\section{Corresponding author}

Hiroshi Kawakami, MD, PhD

Department of Gastroenterology and Hepatology Hokkaido University Graduate School of Medicine Kita 15, Nishi 7, Kita-ku

Sapporo 060-8638

Japan

Fax: +81-11-7067867

hiropon@med.hokudai.ac.jp 